American J. of Engineering and Applied Sciences 2 (3): 565-572, 2009

ISSN 1941-7020

(C) 2009 Science Publications

\title{
Earthquake Resistant Design of Reinforced Soil Structures Using Pseudo Static Method
}

\author{
B. Munwar Basha and G.L. Sivakumar Babu \\ Department of Civil Engineering, \\ Indian Institute of Science, Bangalore, 560012, Karnataka, India
}

\begin{abstract}
Problem statement: This study presented a method to evaluate the internal stability of reinforced soil structures against tension and pullout modes of failure using pseudo-static method for earthquake conditions. Approach: Using limit equilibrium method and assuming the failure surface to be logarithmic spiral, analysis was conducted to maintain internal stability against both tensile and pullout failure of the reinforcements. For the seismic conditions, factors of safety of all the geosynthetic layers in relation to tension and pullout failure modes were determined for different magnitudes of friction angle of backfill, horizontal seismic accelerations and surcharge load acting on the wall. Results: The efforts had been made to obtain the number of layers, pullout length and total length of the reinforcement at each layer level for the desired safety level against tension and pullout modes of failure. The influence of friction angle of the backfill, horizontal earthquake acceleration and surcharge load on number of layers, pullout length and total length of the reinforcement needed for the stability at each level was discussed. Conclusion/Recommendations: The developed method provided a closed form solution for the active earth pressure acting on the reinforced soil structures using rotational log-spiral failure mechanism under earthquake loading ensuring safety against tension and pullout modes of failure.
\end{abstract}

Key words: Factor of safety, log-spiral failure, reinforced earth, tension failure, pullout failure

\section{INTRODUCTION}

Stability analysis of reinforced earth walls under earthquake loading is one of the most important topics in geotechnical engineering and has drawn the attention of researchers. Conventional earth structures are prone to catastrophic failure during earthquakes. In contrast to the conventional retaining structures, Reinforced Soil Structures (RSS) are well known for their improved performance during earthquakes. As such, design procedures are being evolved for such structures considering their stability under earthquake loading and still there exists scope for further development of a simple but improved method to analyze and design such mechanically stabilized walls with inclusions under seismic condition. In the following sections an overview of the performance of RSS during earthquakes, review of the currently developed analyses and the objective and scope of the present study are presented.

The most common approach to seismic stability evaluation of reinforced soil structures is the pseudostatic analysis, which is based on limit equilibrium methods ${ }^{[1,2,7-9]}$. Recently, Choudhury and Ahmad ${ }^{[3-5]}$ presented a seismic stability analysis of waterfront reinforced soil retaining structures using pseudo-static approach. Hence in this study, pseudo-static method is adopted for the stability analysis of RSS.

The focus of the study is to examine the internal stability analysis of RSS when subjected to horizontal and vertical earthquake loading ensuring adequate safety factor against various types of possible failure modes viz. tension and pullout failure of all layers along the depth of wall. The calculation of the tensile strength of reinforcement and the corresponding length required to ensure the internal stability is important in practical terms in the seismic design of RSS. The efforts have been made to derive an analytical solution for the internal seismic stability of RSS considering log-spiral failure surface. Uniformly distributed surcharge load placed on the backfill is also considered in the analysis. In addition to the inertial forces due to backfill soil, the inertial force due to surcharge load is also calculated using the equivalent surcharge height method.

Corresponding Author: G.L. Sivakumar Babu, Department of Civil Engineering, Indian Institute of Science, Bangalore-560 012, Karnataka, India 


\section{MATERIALS AND METHODS}

Consider a RSS of height, $\mathrm{H}$ supporting horizontal cohesionless backfill and the developing failure surface can be represented by a logarithmic spiral as shown in Fig. 1. Logarithmic spiral portion of the failure surface $\left(\mathrm{GH}_{1}\right)$ is governed by height of the reinforced soil slope (EG) and the location of centre of the logarithmic spiral arc (A). The logarithmic spiral starts at the initial radius, $\mathrm{AH}_{1}$ and ends with the final radius, $\mathrm{AG}$ that passes through the center of the logarithmic spiral arc (A). As a result, the location of the center of the logspiral curve (A) can be accurately defined based on the subtended angles $\theta_{1}$ and $\mathrm{H}_{1} \mathrm{NJ}$ as shown in Fig. 2. With reference to Fig. 1 and 2 various terms are defined as follows: $r_{0}=$ Initial radius of the $\log$-spiral $\left(\mathrm{AH}_{1} \mathrm{G}\right)$, $r_{1}=$ final radius of the log-spiral $\left(\mathrm{AH}_{1} \mathrm{G}\right), \theta_{1}=$ Subtended angle of log-spiral $\left(\mathrm{AH}_{1} \mathrm{G}\right), \mathrm{H}_{1} \mathrm{NJ}=$ Angle of the initial radius of the log-spiral $\left(\mathrm{AH}_{1}\right)$ with the horizontal ground surface, IGJ and $\mathrm{H}_{1} \mathrm{IJ}$ are unit weight and friction angle of the backfill.

Reinforcement force required to ensure equilibrium $\left(T_{r}\right)$ : For pseudo-static method, the values of horizontal and vertical inertial forces acting on $\mathrm{SH}_{1} \mathrm{G}$ and due to surcharge load (q) ( $\mathrm{Q}_{\mathrm{h}_{-} \mathrm{SH}_{1} \mathrm{G}}, \mathrm{Q}_{\mathrm{v}_{-} \mathrm{SH}_{1} \mathrm{G}}, \mathrm{Q}_{\mathrm{h}_{-} \mathrm{q}}$ and $\left.\mathrm{Q}_{\mathrm{v}_{-} \mathrm{q}}\right)$ can be calculated using the following equations:

$$
\begin{aligned}
& \mathrm{Q}_{\mathrm{h}_{-} \mathrm{SH}_{1} \mathrm{G}}=\mathrm{k}_{\mathrm{h}} \mathrm{W}_{\mathrm{SH}_{\mathrm{l}} \mathrm{G}} \\
& \mathrm{Q}_{\mathrm{v}_{-} \mathrm{SH}_{\mathrm{G}} \mathrm{G}}=\mathrm{k}_{\mathrm{v}} \mathrm{W}_{\mathrm{SH}_{1} \mathrm{G}} \\
& \mathrm{Q}_{\mathrm{h}_{-} \mathrm{q}}=\mathrm{k}_{\mathrm{h}} \mathrm{q}\left(\mathrm{L}_{\mathrm{g}}-\mathrm{mH}\right) \\
& \mathrm{Q}_{\mathrm{v}_{-} \mathrm{q}}=\mathrm{k}_{\mathrm{v}} \mathrm{q}\left(\mathrm{L}_{\mathrm{g}}-\mathrm{mH}\right)
\end{aligned}
$$

Where

$\mathrm{q}=$ Intensity of surcharge load on the backfill at a distance of $\mathrm{mH}$ from the crest of wall (Fig. 3)

$\mathrm{L}_{\mathrm{g}}=\mathrm{br}_{\mathrm{o}}-\mathrm{H} \cot \alpha$

$\mathrm{W}_{\mathrm{SH}_{1} \mathrm{G}}=$ The weight of the log-spiral, $\mathrm{SH}_{1} \mathrm{G}$

The reinforcement force $\left(T_{r}\right)$ under seismic conditions can be obtained by resolving the forces on $\mathrm{SH}_{1} \mathrm{G}$ horizontally and vertically (Fig. 2) as follows: By considering the horizontal equilibrium condition $(\Sigma \mathrm{H}=0)$ for $\mathrm{SH}_{1} \mathrm{G}$, we get:

$\mathrm{T}_{\mathrm{r}}=\mathrm{Q}_{\mathrm{h}_{-} \mathrm{SH}_{1} \mathrm{G}}+\mathrm{Q}_{\mathrm{h}_{-} \mathrm{q}}+\mathrm{F}_{\mathrm{H}}$

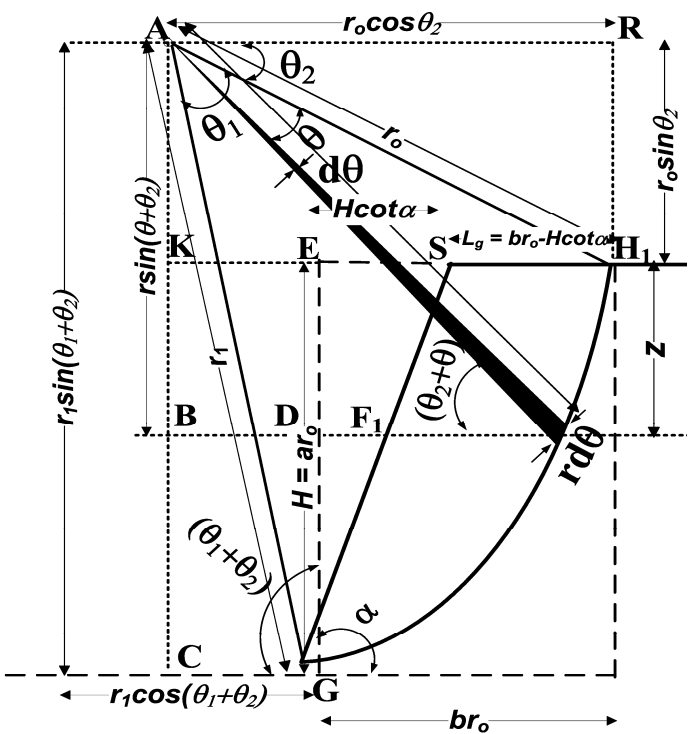

Fig. 1: Geometrical details of RSS

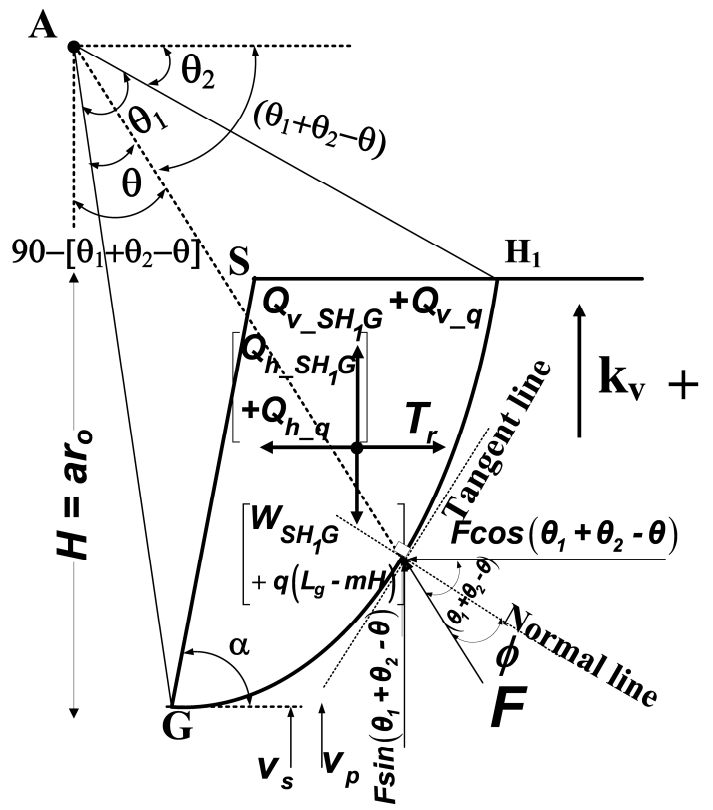

Fig. 2: Forces considered in the analysis Where:

$F_{H}=\int_{0}^{\theta_{1}} F \cos \left(\theta_{1}+\theta_{2}-\theta\right) d \theta=F\left[\sin \left(\theta_{1}+\theta_{2}\right)-\sin \theta_{2}\right]$

$\mathrm{F}=$ Resultant force acting along the radial line of the $\log$ spiral. By considering the vertical equilibrium condition $\left(\sum \mathrm{V}=0\right)$ for $\mathrm{SH}_{1} \mathrm{G}$, we have: 
$\mathrm{F}_{\mathrm{V}}=\mathrm{W}_{\mathrm{SH}_{1} \mathrm{G}}+\mathrm{q}\left(\mathrm{L}_{\mathrm{g}}-\mathrm{mH}\right)-\mathrm{Q}_{\mathrm{v}_{-} \mathrm{SH}_{1} \mathrm{G}}-\mathrm{Q}_{\mathrm{v}_{-} \mathrm{q}}$

Where:

$$
\mathrm{F}_{\mathrm{v}}=\int_{0}^{\theta_{1}} \mathrm{~F} \sin \left(\theta_{1}+\theta_{2}-\theta\right) \mathrm{d} \theta=\mathrm{F}\left[\cos \theta_{2}-\cos \left(\theta_{1}+\theta_{2}\right)\right]
$$

From the Eq. 5 and 7, $\mathrm{T}_{\mathrm{r}}$ can be written as:

$$
\begin{aligned}
\mathrm{T}_{\mathrm{r}}= & \mathrm{Q}_{\mathrm{h}_{-} \mathrm{SH}_{1} \mathrm{G}}+\mathrm{Q}_{\mathrm{h}_{-} \mathrm{q}}+\cot \left(\theta_{1} / 2+\theta_{2}\right) \\
& {\left[\mathrm{W}_{\mathrm{SH}_{1} \mathrm{G}}+\mathrm{q}\left(\mathrm{L}_{\mathrm{g}}-\mathrm{mH}\right)-\mathrm{Q}_{\mathrm{v}_{-} \mathrm{SH}_{1} \mathrm{G}}-\mathrm{Q}_{\mathrm{v}_{-} \mathrm{q}}\right] }
\end{aligned}
$$

Substituting Eq. 1-4 into Eq. 9, the reinforcement force $\left(\mathrm{T}_{\mathrm{r}}\right)$ can be written as:

$$
\begin{aligned}
\mathrm{T}_{\mathrm{r}}= & {\left[\mathrm{k}_{\mathrm{h}}+\left(1-\mathrm{k}_{\mathrm{v}}\right) \cot \left(\theta_{1} / 2+\theta_{2}\right)\right] } \\
& {\left[\mathrm{W}_{\mathrm{SH}_{1} \mathrm{G}}+\mathrm{q}\left(\mathrm{L}_{\mathrm{g}}-\mathrm{mH}\right)\right] }
\end{aligned}
$$

The optimum reinforcement force $\left(\mathrm{T}_{\text {or }}\right)$ is obtained by locating the critical failure surface. The reinforcement force coefficient $(\mathrm{K})$ which can be computed by dividing the optimum force of the reinforcement $\left(\mathrm{T}_{\mathrm{or}}\right)$ with $0.5 \gamma \mathrm{H}^{2}$ as shown below:

$$
\mathrm{K}=\frac{\mathrm{T}_{\text {or }}}{0.5 \gamma \mathrm{H}^{2}}
$$

The magnitude of $\mathrm{K}$ is utilized for computing the factors of safety against tension and pullout modes of failure as explained below.

Expressions for factors of safety: As per the guidelines of $\mathrm{FWHA}^{[6]}$, RSS should be safe against tension failure and pullout failure of the reinforcement.

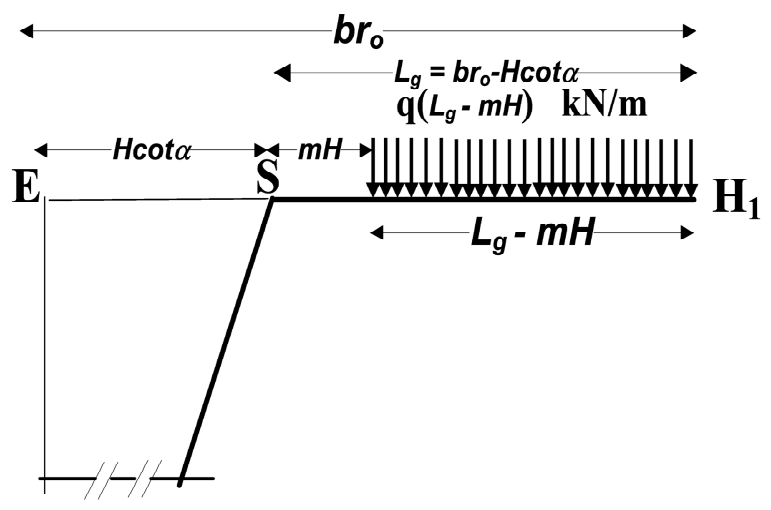

Fig. 3: Distance of surcharge load
The expressions for two modes of failure are presented below.

Factor of safety against tension failure: In this criterion, the ultimate tensile strength of the reinforcement layer $\left(T_{u}\right)$ should be more than the maximum load in the reinforcement layer $\left(\mathrm{T}_{\text {imax }}\right)$. The factor of safety against tension failure $\left(\mathrm{fS}_{\mathrm{t}}\right)$ is given by:

$$
\mathrm{FS}_{\mathrm{t}}=\frac{\mathrm{T}_{\mathrm{u}}}{\mathrm{T}_{\mathrm{imax}}}
$$

where, $T_{i \max }$ based on vertical spacing $\left(\mathrm{S}_{\mathrm{v}}\right)$ and horizontal spacing $\left(\mathrm{S}_{\mathrm{h}}\right)$ is given by:

$$
\mathrm{T}_{\mathrm{i} \max }=(\mathrm{z} \gamma+\mathrm{q}) \mathrm{K}\left(\mathrm{S}_{\mathrm{v}} \times \mathrm{S}_{\mathrm{h}}\right)
$$

where, $S_{v}=H / n, S_{h}=1 \mathrm{~m}, \mathrm{n}=$ number of layers and $\mathrm{z}$ is the depth of the layer under consideration.

Factor of safety against pullout failure: In this case, the available resisting force $\left(\mathrm{P}_{\mathrm{ri}}\right)$ on the embedded reinforcement length $\left(\mathrm{L}_{\mathrm{ei}}\right)$ of layer should be more than the maximum load in the soil reinforcement $\left(\mathrm{T}_{\text {imax }}\right)$ (Fig. 4-6). The factor of safety against pullout failure is given by:

$$
\mathrm{FS}_{\mathrm{po}}=\frac{\mathrm{P}_{\mathrm{ri}}}{\mathrm{T}_{\mathrm{imax}}}
$$

where, $P_{\mathrm{ri}}=2 \sigma_{\mathrm{vi}} \mathrm{L}_{\mathrm{ei}} \tan \delta, \quad \sigma_{\mathrm{vi}}=\mathrm{z} \gamma+\mathrm{q}$ is the effective vertical stress acting on the embedded reinforcement length $\left(\mathrm{L}_{\mathrm{e}}\right)$ and $\delta=$ soil-reinforcement interface friction angle. Total length of the reinforcement $(\mathrm{L})$ required to stabilize the wall can be written as:

$$
\begin{aligned}
\mathrm{L} / \mathrm{H}= & \text { Active length of the reinforcement }\left(\mathrm{L}_{\mathrm{a}} / \mathrm{H}\right) \\
& + \text { pullout length of the reinforcement }\left(\mathrm{L}_{\mathrm{ei}} / \mathrm{H}\right)
\end{aligned}
$$

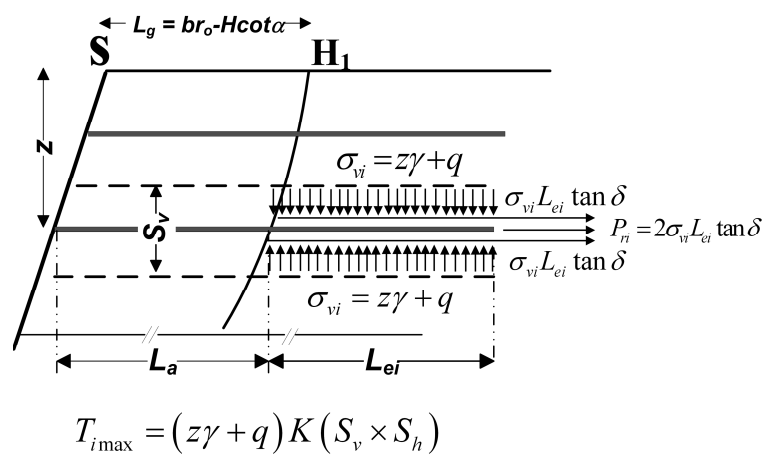

Fig. 4: Pullout length of $\left(\mathrm{L}_{\mathrm{ei}}\right)$ calculation 


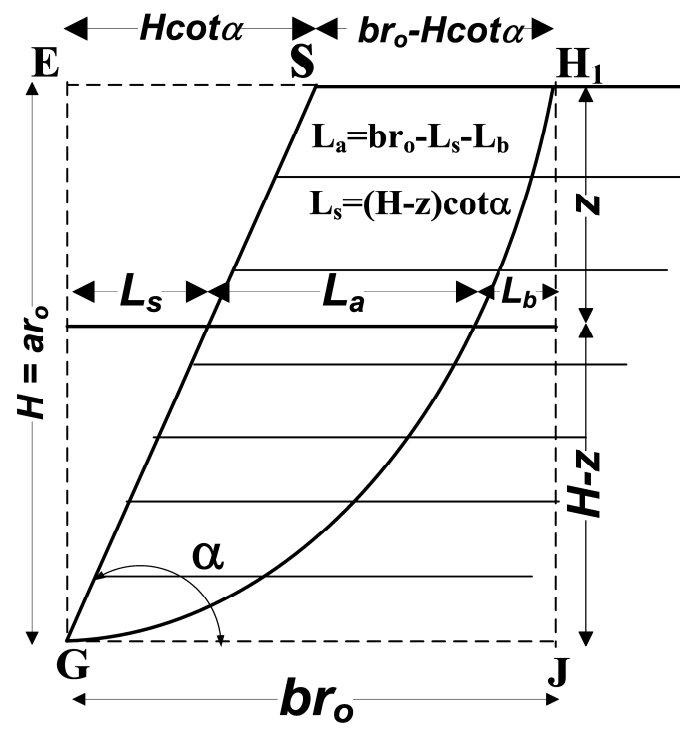

Fig. 5: Active length $\left(\mathrm{L}_{\mathrm{a}}\right)$ calculation

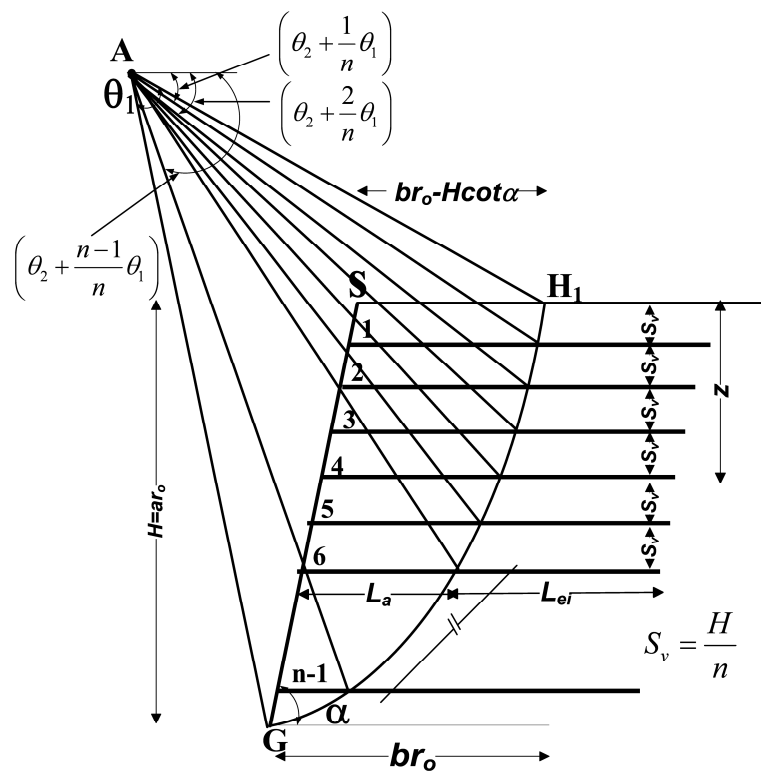

Fig. 6: $\mathrm{L}_{\mathrm{a}}$ and $\mathrm{L}_{\mathrm{ei}}$ for layers

\section{RESULTS AND DISCUSSION}

The stability of RSS can be predicted by substituting the practically acceptable values of the different parameters involved in the factors of safety expressions derived in the above sections. The magnitudes of factors of safety against tension failure $\left(\mathrm{FS}_{\mathrm{t}}\right)$ and pullout failure $\left(\mathrm{FS}_{\mathrm{po}}\right)$ are computed. Effects of these parameters on the tension and pullout stability are presented in Fig. 7-10.

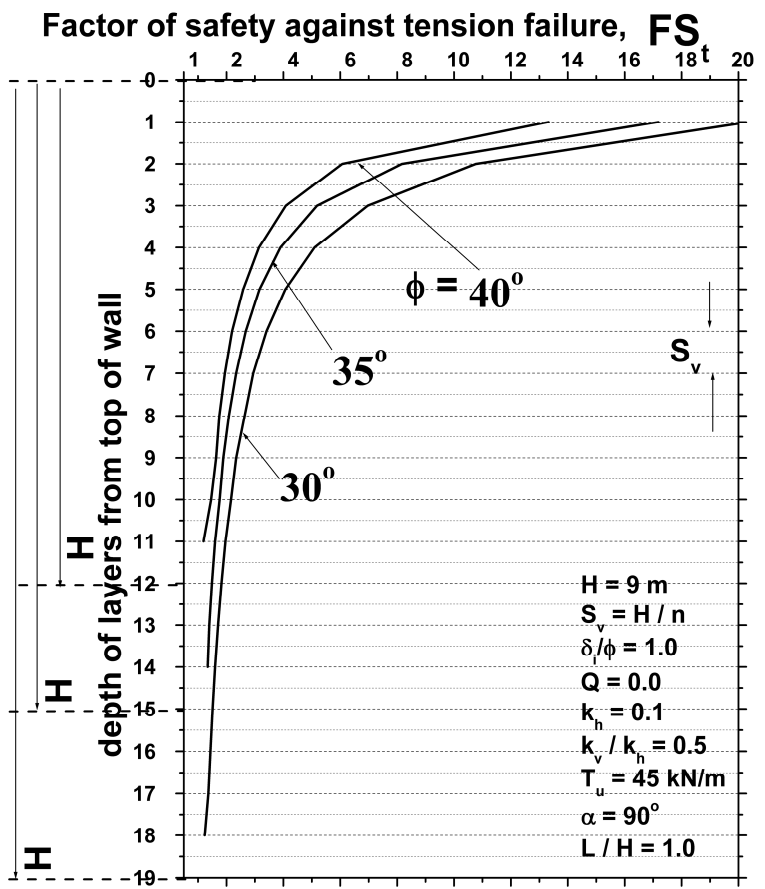

Fig. 7a: Effect of $\phi$ on factor of safety against tension failure $\left(\mathrm{FS}_{\mathrm{t}}\right)$

\section{Design against tension of failure of reinforcement layers: \\ Influence of $\mathbf{k}_{\mathrm{h}}$ and $\mathbf{k}_{\mathrm{v}}$ on $\mathbf{F S}_{\mathbf{t}}$ : Figure $7 \mathrm{a}$ and $\mathrm{b}$ show} the variation of factor of safety against tension failure $\left(\mathrm{FS}_{\mathrm{t}}\right)$ of all the layers of reinforcement along the depth of wall for $\phi=30^{\circ}, 35^{\circ}$ and $40^{\circ}$ and $\mathrm{k}_{\mathrm{h}}=0.0$, $0.1,0.2$ and 0.3 respectively for typical values $\delta / \phi=1.0, \mathrm{~T}_{\mathrm{u}}=45 \mathrm{kN} / \mathrm{m}, \mathrm{Q}=0.0, \mathrm{~m}=0.0, \mathrm{k}_{\mathrm{v}} / \mathrm{k}_{\mathrm{h}}=0.5$ and total length of the reinforcement $(\mathrm{L} / \mathrm{H})=1.0$. For the top layers where axial tensile force in the geosynthetic layer is significantly less, a very high value (more than 18) of factor of safety is observed. It can be seen from Fig. 7a that the bottom layers of reinforcement from the top of wall are more critical to the tension mode of failure due to overburden pressure and generally have lower factor of safety values. For this purpose, the number of reinforcement layers (n) required to maintain the factor of safety against tension failure $\left(\mathrm{Fs}_{\mathrm{t}}\right) \geq 1.0$ for all layers of reinforcement is computed and presented in Fig. 7a and b. As an illustration from Fig. 7b, for $k_{h}=0.0,12$ layers of geosynthetic reinforcement should be provided in the $9 \mathrm{~m}$ height of wall with a vertical spacing $\left(S_{v}\right)$ of $0.75 \mathrm{~m}$ (i.e., $\left.\mathrm{H} / \mathrm{n}=9 / 12\right)$ to obtain $\mathrm{FS}_{\mathrm{t}} \geq 1.0$ for all layers. 


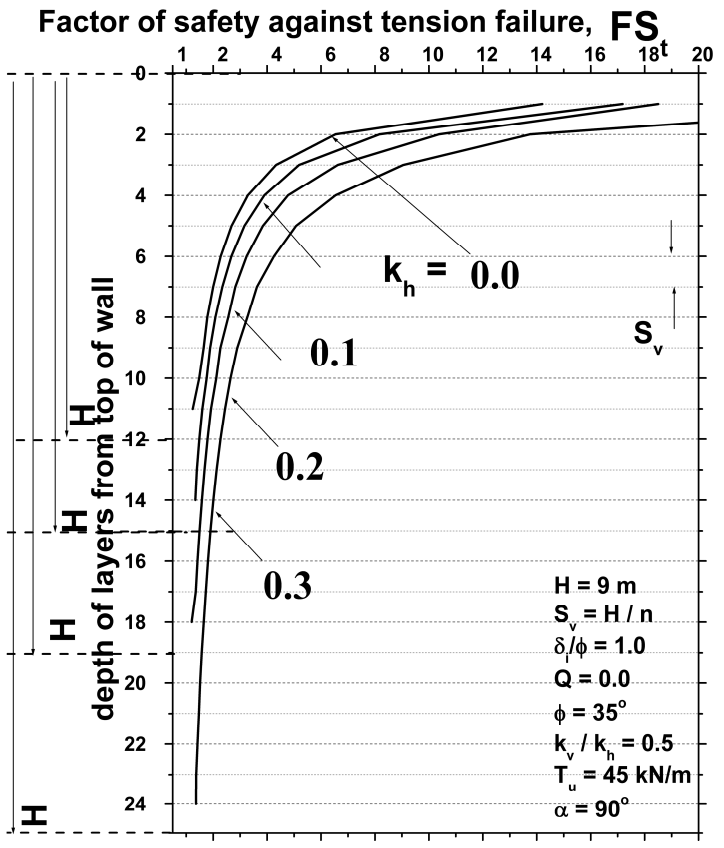

Fig. 7b: Effect of $k_{h}$ on factor of safety against tension failure $\left(\mathrm{FS}_{\mathrm{t}}\right)$

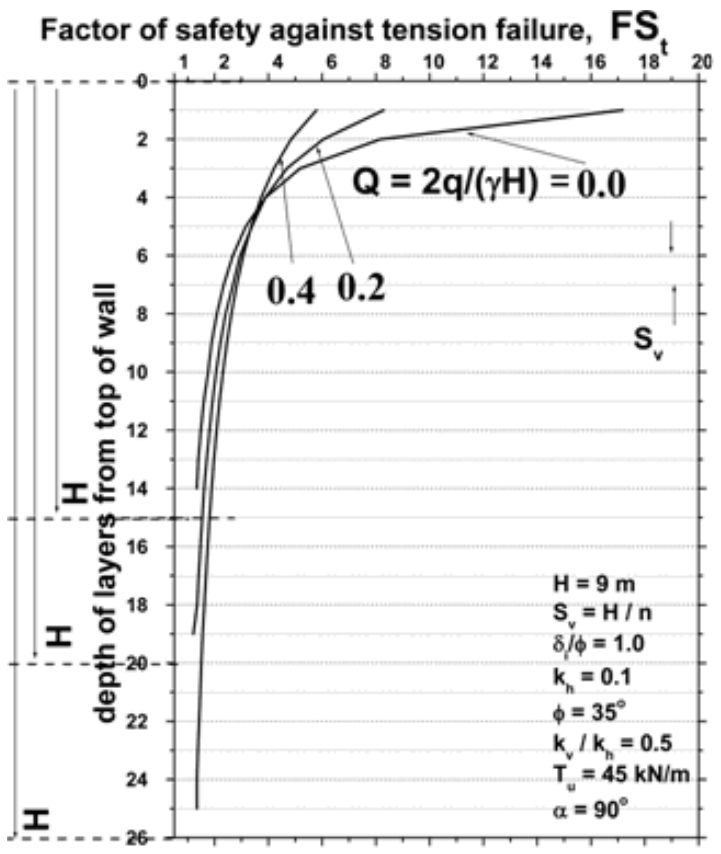

(c)

Fig. 7c: Effect of $\mathrm{Q}=2 \mathrm{q} / \gamma \mathrm{H}$ on factor of safety against tension failure $\left(\mathrm{FS}_{\mathrm{t}}\right)$

It can also be seen from Fig. 7a and $\mathrm{b}$ that number of reinforcement layers (n) required to maintain desired stability $\left(\mathrm{FS}_{\mathrm{t}}>1.0\right)$ should be increased significantly with reduction in $\phi$ value from $40^{\circ}-30^{\circ}$ and increase in $\mathrm{k}_{\mathrm{h}}$ value from $0.0-0.30$. For example, for $\phi=40^{\circ}$, 12 layers of reinforcement should be provided in the $9 \mathrm{~m}$ height of wall with a vertical spacing $\left(\mathrm{S}_{\mathrm{v}}\right)$ of $0.75 \mathrm{~m}$ $(=9 / 12)$ to ob tain $\mathrm{FS}_{\mathrm{t}} \geq 1.0$ for all layers. Similarly $\mathrm{n}=14$ layers for $\phi=35^{\circ}, \mathrm{n}=18$ layers for $\phi=30^{\circ}$ should be accommodated in the $9 \mathrm{~m}$ height of wall to avoid the tension failure of all layers of reinforcement. This behavior is attributed to decreasing shear resistance in the reinforced backfill soil. It can also be observed that for a constant values of $\phi$ and $k_{h}$, the factor of safety $\left(\mathrm{FS}_{\mathrm{t}}\right)$ significantly reduces as the depth of the layer increases. For a constant value of $\mathrm{k}_{\mathrm{h}}=0.2$, factor of safety $\left(\mathrm{FS}_{\mathrm{t}}\right)$ decreases significantly from 20-1.2 when depth increases from the topmost to bottommost layer. Similar observations can also be made for the influence of friction angle. This important observation helps in judicious selection of the number of reinforcement layers as the increase in horizontal seismic accelerations adversely affects the wall stability.

Influence of surcharge load (q) on factor of safety against tension failure $\left(\mathbf{F S}_{\mathrm{t}}\right)$ : If a structure is expected to support a surcharge load, a designer should consider the influence of surcharge load in the wall design calculations. An additional number of layers should be provided in the wall design in order to maintain the desired safety level in relation to tension failure mode when surcharge load is placed on the wall. For this purpose, Fig. 7c is presented to show the influence of uniformly distributed surcharge intensity (defined in terms of surcharge coefficient, $Q=2 q /(\gamma H))$ on the variation of factor of safety against tension failure $\left(\mathrm{FS}_{\mathrm{t}}\right)$ along the depth of wall for typical values adopted in the earlier sections. As an illustration, to avoid tension failure of all layers, number of layers (n) to be accommodated in the $9 \mathrm{~m}$ height of wall are 15, 20 and 26 for $\mathrm{Q}=0.0,0.2$ and 0.4 respectively.

Influence of $\phi, k_{h}$ and $q$ on factor of safety against pullout Failure $\left(\mathrm{FS}_{\mathrm{po}}\right)$ and $\mathbf{L}_{\mathrm{e}} / \mathbf{H}$ : The pullout length of the reinforcement $\left(\mathrm{L}_{\mathrm{ei}}\right)$ gives rise to the stability against pullout failure of RSS. Fig. 8 and 9 show the variation of factor of safety against pullout failure $\left(\mathrm{FS}_{\mathrm{po}}\right)$ and corresponding pullout length $\left(\mathrm{L}_{\mathrm{e}} / \mathrm{H}\right)$ of all the layers of reinforcement along the depth of wall for $\phi=30,35$ and $40^{\circ}$ and $\mathrm{k}_{\mathrm{h}}=0.0-0.3$ respectively for typical value of total length of reinforcement $(\mathrm{L} / \mathrm{H})=1.0$ (uniform for all layers). It can be seen from Fig. 8a and 9a that the upper layers of reinforcement from the top of wall are more critical to the pullout mode of failure 


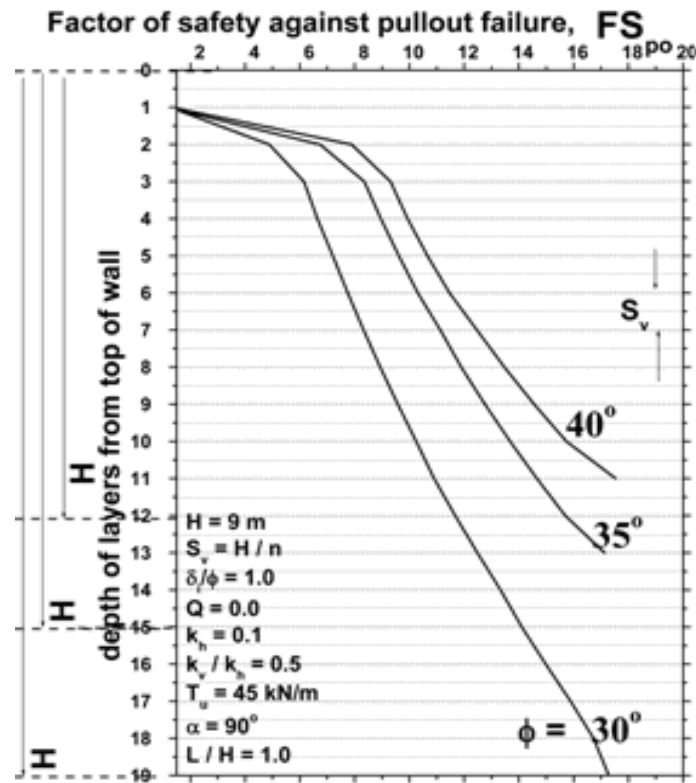

Fig. 8a: Influence of $\phi$ on factor of safety against pullout failure $\left(\mathrm{FS}_{\mathrm{po}}\right)$ along the depth of wall, computed for $\mathrm{L} / \mathrm{H}=1.0$

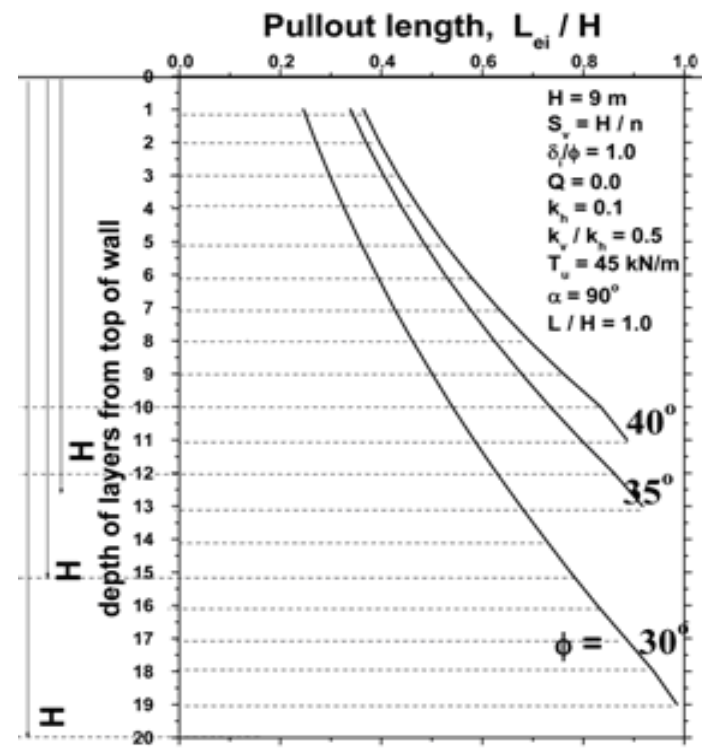

Fig. 8b: Influence of $\phi$ on pullout length of geosynthetic layer $\left(\mathrm{L}_{\mathrm{e}} / \mathrm{H}\right)$ along the depth of wall for $\mathrm{L} / \mathrm{H}=1.0$

and wall should have adequate pullout length to maintain the factor of safety against pullout failure $\left(\mathrm{FS}_{\mathrm{po}}\right)$. From Fig. $8 \mathrm{~b}$ and $9 \mathrm{~b}$, it can be obtained that the contribution of pullout length for all the layers required to be provided in the wall, which are already established in Fig. 7a and b.
Factor of safety against pullout failure, FS

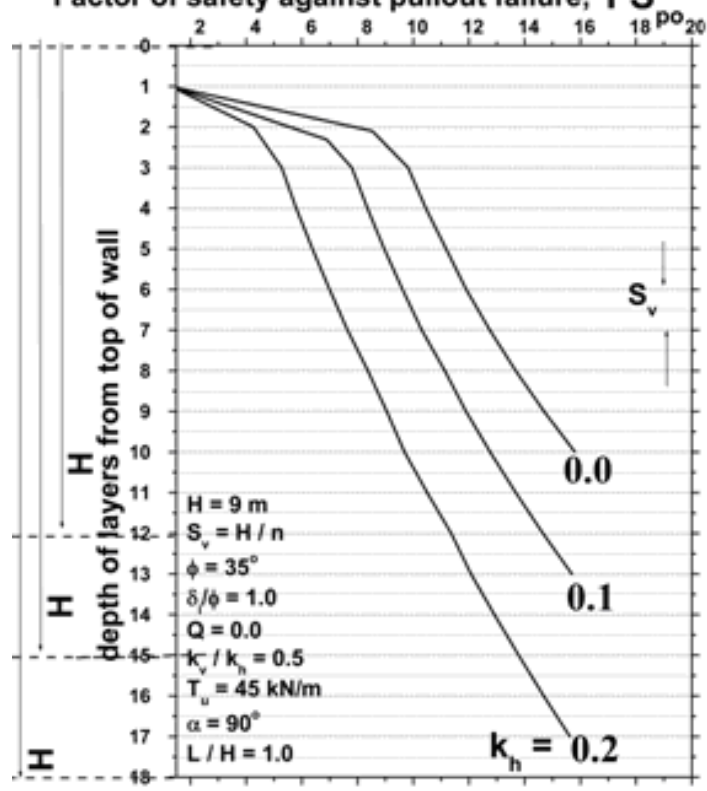

Fig. 9a: Influence of $k_{h}$ on factor of safety against pullout failure $\left(\mathrm{FS}_{\mathrm{po}}\right)$ along the depth of wall, computed for $\mathrm{L} / \mathrm{H}=1.0$

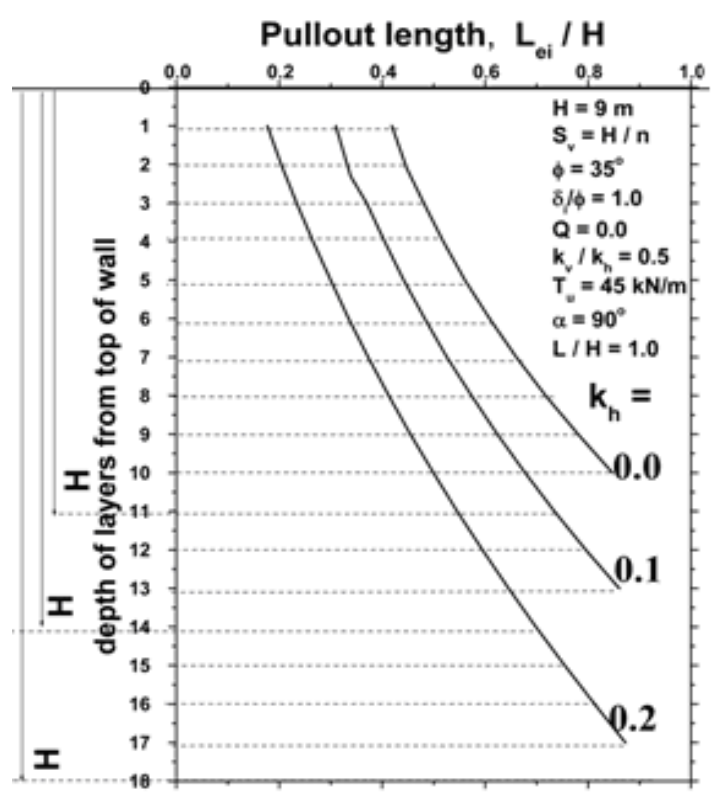

Fig. 9b: Influence of $k_{h}$ on pullout length of geosynthetic layer $\left(\mathrm{L}_{\mathrm{e} i} / \mathrm{H}\right)$ along the depth of wall for $\mathrm{L} / \mathrm{H}=1.0$

Results presented in Fig. 8a and 9a demonstrate that for a constant value of $\mathrm{k}_{\mathrm{h}}$ and $\mathrm{L} / \mathrm{H}=1.0$, i.e., $\mathrm{L}=$ $9 \mathrm{~m}$, the factor of safety $\left(\mathrm{FS}_{\mathrm{po}}\right)$ significantly increases as the depth of the layer increases. For illustration, 


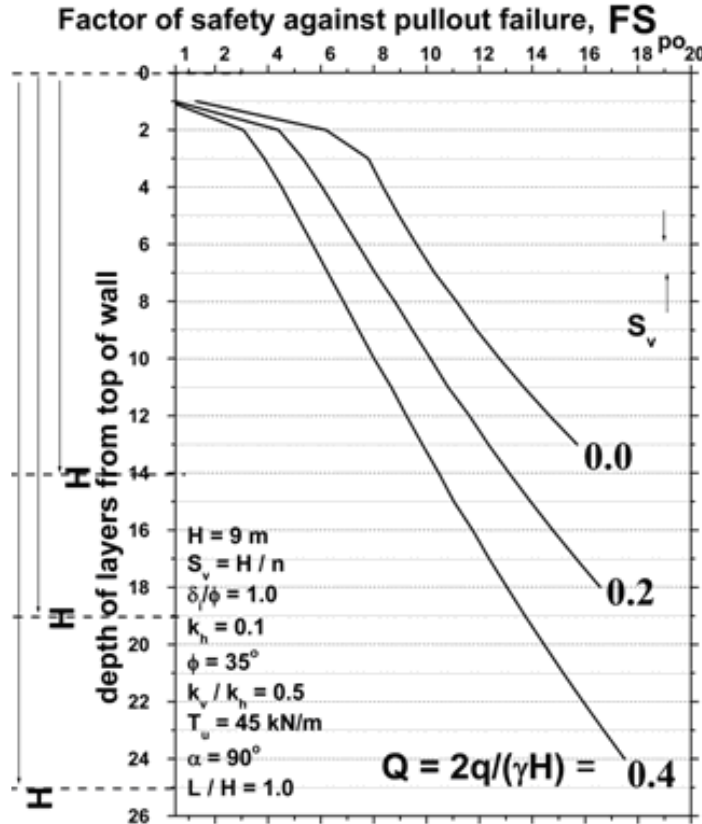

Fig. 10a: Influence of $\mathrm{Q}=2 \mathrm{q} /(\gamma \mathrm{H})$ on factor of safety against pullout failure $\left(\mathrm{FS}_{\mathrm{po}}\right)$ along the depth of wall, computed for $\mathrm{L} / \mathrm{H}=1.0$

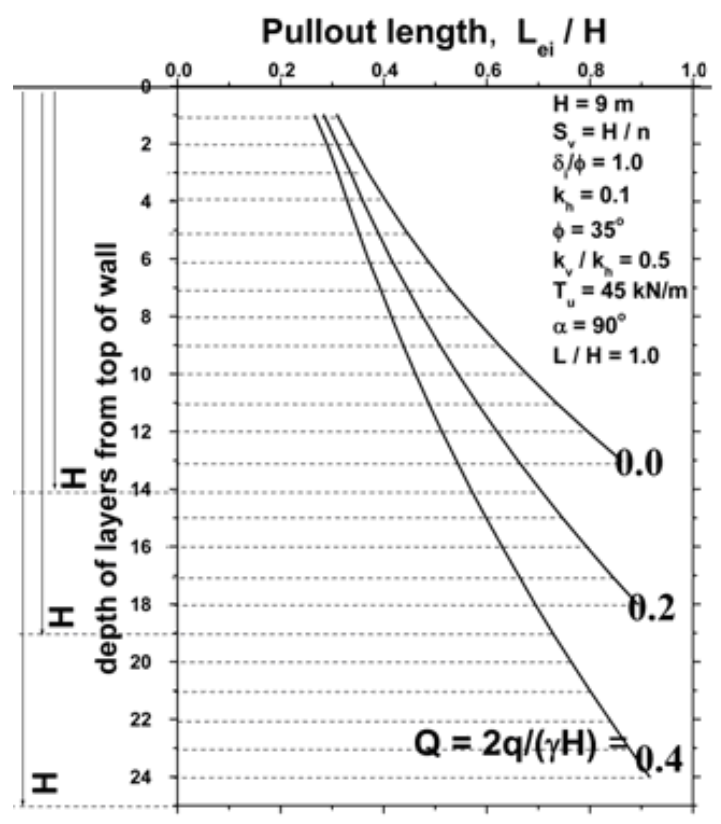

Fig. 10b: Influence of $\mathrm{Q}=2 \mathrm{q} /(\gamma \mathrm{H})$ on pullout length of geo-synthetic layer $\left(\mathrm{L}_{\mathrm{e}} / \mathrm{H}\right)$ along the depth of wall for $\mathrm{L} / \mathrm{H}=1.0$

for constant value of $\mathrm{k}_{\mathrm{h}}=0.1$ (Fig. 8a), the factor of safety $\left(\mathrm{FS}_{\mathrm{po}}\right)$ increases significantly from 1.5-15.5 when depth increases from the topmost layer (1st layer) to bottommost layer (13th layer). This is because, the available pullout length $\left(\mathrm{L}_{\mathrm{ei}} / \mathrm{H}=\mathrm{L}_{\mathrm{a}} / \mathrm{H}\right)$ for $\mathrm{k}_{\mathrm{h}}=0.1$ in Fig. 9b, increases from 0.3-0.8 as depth increases from the uppermost layer (1st layer) to the bottommost layer (13th layer). An observation that can also be made from Fig. $8 b$ and $9 b$ is that the available pullout length $\left(\mathrm{L}_{\mathrm{ei}} / \mathrm{H}\right)$ reduces as the magnitude of friction angle $(\phi)$ decreases from $40-30^{\circ}$ and $k_{h}$ value increases from 0.0 0.3. Similar observations can also be made from the results presented in Fig. 10a and b for the influence of surcharge load (q).

\section{CONCLUSION}

The present study gives a simple design methodology for analyzing the reinforced soil structures subjected to earthquake forces for the internal stability of reinforced soil structures in the context of a pseudostatic limit equilibrium method using the logarithmicspiral failure mechanism. A closed-form solution is obtained to estimate seismic active earth pressure acting on reinforced earth structures and the factors of safety against tension and pullout modes of failure. The design parameters such as the horizontal seismic accelerations, number of reinforcement layers, pullout length and total length of the reinforcement, angle of shearing resistance, uniformly distributed surcharge load have significant influence on the internal seismic stability of the wall. It is noted that the bottom layers of reinforcement from the top of wall are more critical to the tension mode of failure due to axial tensile force in the geosynthetic layer is significantly high and have lower factor of safety values. Further, it is observed that the upper layers of reinforcement from the top of wall are more critical to the pullout mode of failure and wall should have adequate pullout length to maintain the targeted value of factor of safety in pullout mode.

\section{REFERENCES}

1. Basha, B.M. and P.K. Basudhar, 2005. Pseudostatic seismic stability analysis of geosynthetic reinforced soil retaining walls. Indian Geotech. J., 35: 323-348. http://www.igsjournal.org/

2. Bathurst, R.J. and Z. Cai, 1995. Pseudo-static seismic analysis of geosynthetic reinforced segmental retaining walls. Geosynthet. Int., 2: 787-830. http://www.geosyntheticssociety.org/gi/GI_V2N5.htm

3. Choudhury, D. and S.M. Ahmad, 2007. Stability of waterfront retaining wall subjected to pseudo-static earthquake forces. Ocean Eng., 34: 1947-1954. DOI: 10.1016/j.oceaneng.2007.03.005 
4. Choudhury, D. and S.M. Ahmad, 2008. Reply to discussion on stability of waterfront retaining wall subjected to pseudo-static earthquake forces by Ivo Bellezza and Roberta Fentini. Ocean Eng., 35: 1567-1568. DOI: 10.1016/j.oceaneng.2008.07.005

5. Choudhury, D. and S.M. Ahmad, 2009. External stability of waterfront reinforced soil structures under seismic conditions using a pseudo-static approach. Geosynthet. Int., 16: 1-10. DOI: 10.1680/gein.2009.16.1.1

6. FHWA., 2001. Mechanically stabilized earth walls and reinforced soil slopes: Design and construction guidelines. Publication FHWA NHI-00-43. Federal Highway Administration and National Highway Institute, Washington, DC., USA. http://www.ntis.gov/search/product.aspx?abbr=PB 2001105041
7. Ismeik, M. and E. Guler, 1998. Effect of wall facing on the seismic stability of geosyntheticreinforced retaining walls. Geosynthet. Int., 5: 41-53. http://direct.bl.uk/bld/PlaceOrder.do?UIN=073646 $625 \&$ ETOC $=$ RN\& from $=$ searchengine

8. Ling, H.I. and D. Leshchinsky, 1998. Effects of vertical acceleration on seismic design of geosynthetics reinforced soil structures. Geotechnique, 48: 347-373. http://cat.inist.fr/?aModele $=$ afficheN\&cpsidt $=2397$ 406

9. Ling, H.I., D. Leshchinsky and E.B. Perry, 1997. Seismic design and performance of geosynthetic reinforced soil structures. Geotechnique, 47: 933-952. http://cat.inist.fr/?aModele $=$ afficheN\&cpsidt $=2085$ 026 